Rodelo, M., y Chamorro, C. (2020). Competencias genéricas en los programas de contaduría pública: el caso de la Universidad del Atlántico entre los períodos 2016 al 2018. Contaduría Universidad de Antioquia, 77, 81-107. Doi:https://doi.org/10.17533/udea.rc.n77a03

\title{
Competencias genéricas en los programas de Contaduría Pública: el caso de la Universidad del Atlántico entre los periodos 2016 al 2018
}

\author{
Mario Alberto Rodelo Sehuanes \\ mrodelo011@gmail.com \\ Universidad del Atlántico \\ Orcid: 0000-0002-3738-6395
}

Candy Lorena Chamorro González candiilorena@gmail.com Universidad Católica Luis Amigo

Orcid: 0000-0001-7332-8566 
Competencias genéricas en los programas de Contaduría Pública: el caso de la Universidad del Atlántico entre los periodos 2016 al 2018

Resumen: En las Instituciones de Educación Superior, formar sujetos (Contables) con altas competencias en el campo profesional y humano, es cada vez más imperante a la luz de las nuevas prácticas educativas. Asi pues, surge la necesidad de analizar los resultados (de las competencias genéricas) del Examen de Calidad de la Educación Superior (Saber Pro) del programa de contaduría pública de la Universidad del Atlántico entre los periodos 2016 al 2018, con el objetivo de reflexionar la formación en competencias y cualidades humanas recibidas para el ejercicio profesional. El enfoque metodológico es cuantitativo sustentado en un alcance descriptivo, de análisis de datos provenientes de las pruebas Saber Pro. Los resultados demuestran que los estudiantes de contaduría pública de la Universidad del Atlántico entre los periodos 2016 al 2018, superan la media nacional en su grupo de referencia, autenticando un buen nivel de competencias para su desenvolvimiento profesional y de desarrollo humano.

Palabras claves: Educación superior, Competencias Genéricas, Contaduría Pública.

Generic competencies in public accounting programs: The case of Universidad del Atlántico between the period $2016-2018$

Abstract: Training (accounting) individuals with high competencies in the professional and human fields is an increasingly imperative need for Higher Education Institutions in the light of the new educational practices. Hence, the need arises to analyze the (generic competencies) results in the Higher Education Quality Exam (Saber Pro) of the Public Accounting program from Universidad del Atlántico between the period 2016 - 2018, with the aim of reflecting on the training in competencies and human qualities received for professional practice. The methodological approach is quantitative and is supported in a descriptive scope, with analysis of data from the Saber Pro tests. The results show that Public Accounting students at Universidad del Atlántico between 2016 - 2018 exceed the national average in their reference group, confirming a good level of competencies for their professional and human development performance.

Keywords: Higher education, generic competencies, Public Accounting.

Competências genéricas nos programas de Contabilidade Pública: o caso da Universidade do Atlântico entre os periodos 2016 a 2018

Resumo: Nas Instituições de Educação Superior, formar sujeitos (contábeis) com altas competências no campo profissional e humano, é cada vez mais predominante à luz das novas práticas educativas. Assim, surge a necessidade de analisar os resultados (das competências genéricas) do Exame de Qualidade da Educação superior (Saber Pro) do programa de Contabilidade Pública da Universidade do Atlâtico entre os períodos 2016 a 2018, com o intuito de refletir sobre a formação em competências e qualidades humanas recebidas para o exercicio profissional. O enfoque metodológico é quantitativo sustentado em um alcanço descritivo, de análise dos dados obtidos da prova Saber Pro. Os resultados demonstram que os estudantes de Contabilidade Pública da Universidade do Atlântico entre os periodos 2016 a 2018 , superam a média nacional no seu grupo de referência, conferindo um bom nivel de competências para o seu desempenho profissional e de desenvolvimento humano.

Palavras chave: Educação superior, competências Genéricas, Contabilidade Pública.

Compétences génériques dans les programmes de Comptabilité Publique : Le cas de l'Université de l'Atlantique comprennant la période 2016 - 2018

Résumé: Dans les établissements d'enseignement supérieur, la formation de sujets (comptables) hautement qualifiés dans le domaine professionnel et humain devient de plus en plus prédominante à la lumière des nouvelles pratiques éducatives. Il devient donc nécessaire d'analyser les résultats (des compétences génériques) de l'Examen de Qualité de l'Enseignement Supérieur (Saber Pro) du programme de comptabilité publique de l'Université de l'Atlantique entre 2016 et 2018, dans le but de réfléchir à la formation en compétences et qualités humaines reçues pour l'exercice professionnel. L'approche méthodologique est quantitative fondée sur une portée descriptive d'analyse des données provenant des examens Saber Pro. Les résultats montrent que les étudiants en comptabilité publique de l'Université de l'Atlantique entre 2016 et 2018 dépassent la moyenne nationale dans leur groupe de référence, en authentifiant un bon niveau de compétences pour leur développement professionnel et leurs développement humain.

Mots clés: enseignement supérieur, compétences génériques, comptabilité publique. 
Cont. udea (julio-diciembre), pp. 81-107. (c) Universidad de Antioquia-2020.

\title{
Competencias genéricas en los programas de Contaduría Pública: el caso de la Universidad del Atlántico entre los periodos 2016 al 2018
}

\author{
Mario Alberto Rodelo Sehuanes y Candy Lorena Chamorro González. \\ https://doi.org/10.17533/udea.rc.n77a03
}

Primera versión recibida en mayo de 2020 - Versión final aceptada en agosto de 2020

\section{Introducción}

as dinámicas que se desarrollan en el mundo de hoy, son respuesta a Lun cúmulo de avatares y de discusión en la estructuración de un nuevo mundo económico, social y político. Gracia (2002) afirma que las valoraciones instrumentales y tradicionales de la educación, impartidas sobre la contabilidad, son discusiones históricas acerca del componente educativo en las que se debe concertar; así pues, cuando investigan en educación contable, se refieren a una crisis sistemática de la educación (Franco, 2011). Es por esto que la generación de nuevo conocimiento se considera el camino hacia la modificación de las líneas paradigmáticas de acción entre el qué hacer y saber hacer (Martínez, 2007).

En este sentido, es significativo precisar que hoy en día aún se mantiene y se profundiza la visión instrumental de la educación sobre la contabilidad, recreando ciertos lineamientos académicos basado en la formación técnica y habilidades en la representación de la información; así pues, el proceso de formación en investigación y en las áreas sociales, se mantiene en un segundo plano a pesar del desarrollo socioeconómico de la sociedad y las valoraciones sobre la rama investigativa en el proceso económico del país, tal y como lo expresa Franco (2011): "la educación carece de procesos cognoscitivos, que permitan el descubrimiento de nuevos hechos y fenómenos, la formación de relaciones generalizadas y la invención de instrumentos mentales y materiales para complementar las actividades humanas" (p. 121).

En la actual dinámica todas las disciplinas requieren que su soporte sea respaldado por una estructura científica y tecnológica, asumiendo y 
Rodelo, M., y Chamorro, C. Competencias genéricas en los programas de contaduría pública...

desarrollando un papel fundamental en el desarrollo teórico del conocimiento e interdisciplinar de un profesional para el nuevo mundo, un sujeto contable globalizado, un estudiante de contaduría pública que posea competencias para el buen devenir de la profesión.

Sin duda, el desarrollo histórico de la educación contable se interconecta con la luz de nuevas teorías educativas, sociales y de regulación contable, que volcó a la proliferación de competencias para el mercado de los futuros sujetos contables con miras a poder estructurar nuevas tensiones de la formación integral del estudiante de contaduría pública, buscando la preponderancia de las competencias inherentes a la contabilidad y de las cualidades humanas del ser.

Hoy por hoy el hecho de adentrarse en el amplio campo de las competencias, presenta una discusión dual, aplicación y evaluación en el campo formativo, pero sobre todo en aquellas denominadas competencias genéricas, donde el nuevo sistema-mundo y las correlaciones existenciales en la formación del sujeto contable, llaman a que este nuevo perfil recreado en la sociedad del conocimiento; no debe solo potencializar el conocimiento técnico, tecnológico e instrumental, sino también, el conocimiento de corte científico, cognitivo, social, ético y humano (Macagnan, 2013).

Tal y como lo respaldan González y González (2008), dentro del marco de la sociedad del conocimiento en la formación del profesional, las universidades deben garantizar "la formación de motivaciones, valores, habilidades y recursos personales que le permitan desempeñarse con eficiencia, autonomía, ética y compromiso social en contextos diferentes, heterogéneos y cambiantes" (p.190); así mismo, deben responsabilizarse con la formación de un "profesional capaz de gestionar el conocimiento necesario para el desempeño eficiente de su profesión durante toda la vida a través de la utilización de las TIC” (p.191).

En ese sentido, la implementación de las competencias genéricas en la formación universitaria, toman mucha importancia, cuando en el mundo laboral propiamente dicho, no solo se logra hacer una evaluación sobre los conocimientos y/o competencias técnicas, sino también, la capacidad de este en desenvolverse en un ambiente ampliamente humano y ético; es decir, potenciar las cualidades humanas.

El presente documento toma una relevancia particular debido a que tiene como objetivo analizar los resultados de las competencias genéricas del Examen de Calidad de la Educación Superior (Saber Pro) de los estudiantes de contaduría pública de la Universidad del Atlántico, permitiendo verificar y reflexionar si los sujetos contables en formación presentan una distinción positiva en los conocimientos integrales referenciados en dichas pruebas para el ejercicio profesional. 


\section{Competencias en la sociedad del conocimiento}

En la actual sociedad reinante o a lo que Habermas llamaría el mundo de la vida como resultado de los incesantes cambios no solo económicos, políticos, sino culturales y sobre todo de la información, lo que Rober Lane acuñaría por primera vez en 1966 (Vega, 2015) "la sociedad del conocimiento", ha conducido a nuevas mutaciones industriales, informativas, organizacionales, políticas y hasta educativas, donde la formación profesional debe introducir nuevas cualidades reformativas (Competencias), capaces de prosperar y adaptarse a en el nuevo mundo.

Es por eso que la educación superior colombiana requiere un cambio sistemático frente a las nuevas realidades y complejidades del nuevo mundo, generando así dentro de las Instituciones de Educación Superior ciertos retos frente a los avatares del desarrollo social, económico y educativo en la sociedad del conocimiento; frente a esto, Pérez (2012), proyecta algunos de estos retos, como son la incorporación de nuevas tecnologías a los procesos educativos y la formación investigativa con capacidad para aportar soluciones a las necesidades y problemáticas del contexto. Una educación integral que por medio de las competencias faciliten la integración de las competencias del ser humano, del ser, estar, saber, y saber hacer (Kincheloe et al., 2004, citado en Mérida y García, 2005).

Así pues, la enseñanza universitaria debe girar a las nuevas prácticas formativas - competencias - para el desarrollo de la innovación en los estudiantes de educación superior; es decir, la educación superior necesita conformar cuerpos de conocimientos y una masa crítica, que además de dar cuenta de su propio quehacer, promueva la generación de teorías y proyectos.

$\mathrm{Si}$ bien todo lo anterior es lo que demarca el deber ser de la funcionalidad de la educación superior, existen tensiones al momento de preestablecer el concepto de competencia dentro de las profesiones y disciplinas dado el metalenguaje usado en cada una de ellas, por ejemplo, profesiones como las liberales (Contaduría Pública), o las ingenierías, la arquitectura o la medicina, reciben más directamente el influjo de fuerzas externas como el trabajo y la sociedad (Maldonado, 2010); es decir, depende mucho de las regulaciones y/o aportes de teorías abstraídas propiamente de la praxis (Barnett 2001, citado en Maldonado, 2010), además del papel que juegan las instituciones en la emisión de pautas y directrices frente a la caracterización formativa de esta.

En este sentido, las competencias-genéricas tienen un papel fundamental en la educación superior porque estas compilaciones le permiten al estudiante adquirir actitudes mixtas que a su vez generan resultados de entendimiento, prácticas y desacuerdos; reconocidos como elementos primordiales que debe poseer todo profesional. Sin embargo, Chan et al. (2017) afirman que el 
Rodelo, M., y Chamorro, C. Competencias genéricas en los programas de contaduría pública...

desarrollo y la implementación de competencias-genéricas en la educación superior presenta múltiples desafíos que se han venido mitigando con el tiempo, pero aún persisten en términos de pedagogía y evaluación, así como las percepciones de los profesores y estudiantes sobre las competencias-genéricas. Situación que no es indiferente en los programas de Contaduría Pública.

Por ende, Zlatkin et al. (2015) afirman que las competencias-genéricas deben mantener una rigurosa estructura de diseño e implementación, en la cual tanto el docente como el estudiante integren la lógica de estas competencias en términos de enseñanza y aprendizaje. No obstante, las competencias genéricas son un complemento esencial para las competencias específicas, ya que ambas están orientadas hacia una meta igualitaria, lograr que los estudiantes adhieran información tangible sobre la preparación para el trabajo, la empleabilidad de los estudiantes y la creación de empresarios innovadores y socialmente responsables.

\section{Competencias en la formación del estudiante de contaduría pública}

La formación de los estudiantes de contaduría pública del país, está llamada a responder no solo a los cambios generativos de índole económico, financiero o de regulación, sino también a los cambios generativos de corte socio-humanístico del territorio, como una integralidad formativa y competente del estudiante. Una educación contable que recree un sujeto plenamente competente a la luz de los nuevos contextos y realidades del entorno donde se desarrolle.

Así pues, existen organismos nacionales e internacionales que emiten ciertas directrices sobre la educación contable, como lo es el caso de la Federación Internacional de Contadores -IFAC- que preestablecen unos lineamientos internacionales de educación contable, basada en ciertas investigaciones y proyectos emanados en la lógica económica y financiera de los países. Sin embargo, Barnett (2011) preestablece que ciertas competencias han de ser adquiridas también desde el mundo académico, pero deben estar orientadas y reguladas, especialmente, por lo que ocurre en el mundo científico, profesional, social y cultural.

En ese sentido, el futuro profesional debe ser alguien con un aprendizaje permanente en valores, capacidades, destrezas y competencias, pero no solo técnicas, sino también socio-investigativas, con el fin de que sirva de eje articulador entre la teorización y la praxis contable, es decir, la base que constituye la formación integral del estudiante de contaduría pública a la luz de las nuevas prácticas y realidades, son las competencias (Valera, 2009).

En aras de precisar y articular la formación profesional del estudiante de contaduría pública y las competencias que este debe tener bajo la preponderancia de lineamientos institucionales, se reconoce que bajo las 
lógicas actuales del sistema-mundo, la información de toda índole constituye un flujo de aspectos y discursos fundamentales frente al espectro de la transformación educativa de manera global, que esto responde a unos discursos y lineamentos de verdad emitidos especialmente por organismos o instituciones nacionales e internacionales en su gran mayoría.

Entiéndase como parte adicional, la esencia de las instituciones y su papel en el desarrollo económico, político, social, y en este caso educativo de una sociedad, como bien la caracteriza Veblen (1971): "las instituciones son, en sustancia, hábitos mentales predominantes con respecto a relaciones y funciones particulares del individuo y de la comunidad" (p.196), o lo que tiempo más tarde North (1990) precisaría: "las instituciones son las reglas de juego en una sociedad o más formalmente, son los dispositivos de coacción inventados por los humanos que amoldan la interacción humana” (p. 410).

En ese sentido, se presenta a continuación, lo expresado y emitido por parte de algunas instituciones internacionales y nacionales, las distintas referencias hacia la formación de competencias en el campo educativo-contable, particularizando al final las aproximaciones a las competencias de interés de este trabajo.

\section{III.I. En el aspecto internacional}

El organismo International Federation of Accountants (IFAC) es el máximo referente a nivel internacional sobre los aspectos profesionales, especialmente las educativas. Valero et al., (2013), expresa por medio de las tablas 1 y 2 un análisis de las distintas variaciones sobre el entendimiento de competencia emitido por esta institución en la formación de profesionales de la contabilidad.

Tabla 1: Comparativo de conceptos de capacidad y competencia.

\begin{tabular}{ll}
\hline \multicolumn{1}{c}{ Capacidad } & \multicolumn{1}{c}{ Competencia } \\
\hline - Atributos -Potencial- Poseer. & - Acciones - Real- Demostrar. \\
- Es el resultado final del aprender. & - Es el resultado final de trabajar \\
- Es conocimiento teórico y profesional, técnicas & $\begin{array}{l}\text { - Un número de resultados u objetos cumplidos } \\
\text { de organización, de habilidades. Enmarcados en }\end{array}$ \\
valores, en ética y actitud. & en cuanto a normas de calidad, funcionales \\
& yerenciales. Enmarcados en resultados \\
& acorde con estándares de comportamiento, \\
& demostración efectiva de su desempeño. \\
\hline
\end{tabular}

Concepto de competencia del Consejo de Normas Internacionales de Formación en Contaduría, 2008:

Ser capaz de realizar una tarea con un estándar de calidad definido en entornos reales de trabajo. Explicación: La competencia se refiere a la aptitud demostrada para cumplir con papeles o tareas pertinentes cumpliendo con estándares definidos. Mientras que las capacidades se refieren a los atributos adquiridos por los individuos que les dan la capacidad de actuar, la competencia se refiere a la demostración efectiva del desempeño. La competencia se puede evaluar a través de una variedad de medios, incluido el desempeño en el lugar de trabajo, o mediante simulaciones del contexto laboral, exámenes escritos y orales, y auto-evaluación.

Fuente: Elaboración propia basado en Valero-Patiño-Duque (2013). 
Rodelo, M., y Chamorro, C. Competencias genéricas en los programas de contaduría pública...

Es significativo mencionar que las comparaciones entre los conceptos "calidad" y "competencias" son expresadas a partir del marco conceptual de los Pronunciamientos Internacionales de Formación (2007) y el establecimiento de competencia por el Consejo de Normas Internacionales de Formación en Contaduría en 2008. La tabla 1 permite analizar que existe una diferencia puntual en términos; sin embargo, es fundamental fomentar el aprendizaje de ambos elementos ya que estos son necesarios para desarrollar una educación de calidad, que impacte en el ejercicio humanístico y profesional en los estudiantes de contaduría pública.

Tabla 2: Análisis del concepto de competencia encontrado en las Normas Internacionales de Formación.

\begin{tabular}{|c|c|c|}
\hline Norma & Nombre & Concepto de competencia \\
\hline IES 1 & $\begin{array}{l}\text { Requisitos de ingreso a un } \\
\text { programa de formación } \\
\text { profesional en Contaduría. }\end{array}$ & $\begin{array}{l}\text { Todos los aspirantes deben alcanzar un nivel de competencia } \\
\text { comparable en el momento de su ingreso. }\end{array}$ \\
\hline IES 2 & $\begin{array}{l}\text { Contenido de los programas } \\
\text { profesionales de formación } \\
\text { en Contaduría }\end{array}$ & $\begin{array}{l}\text { El componente de la tecnología de la información debe incluir } \\
\text { los siguientes temas y competencias: (a) conocimiento general } \\
\text { de la tecnología de la información; (b) conocimiento del } \\
\text { control de la tecnología de la información; (c) competencias del } \\
\text { control de la tecnología de la información; (d) competencias } \\
\text { del usuario de la tecnología de la información; y (e) una o una } \\
\text { mezcla de las competencias correspondientes a las funciones } \\
\text { gerenciales, de evaluación y de diseño de los sistemas de } \\
\text { información }\end{array}$ \\
\hline IES 3 & $\begin{array}{l}\text { Habilidades profesionales y } \\
\text { formación general. }\end{array}$ & $\begin{array}{l}\text { Los aspirantes a asociarse a un organismo miembro de } \\
\text { IFAC deben estar dotados de la adecuada combinación de } \\
\text { conocimientos y destrezas (intelectuales, técnicos, personales, } \\
\text { interpersonales y organizacionales) para desarrollarse como } \\
\text { contadores profesionales. Esto les permite actuar de manera } \\
\text { competente como contadores profesionales a lo largo de su } \\
\text { carrera en entornos cada vez más complejos y exigentes. }\end{array}$ \\
\hline IES 5 & $\begin{array}{l}\text { Requisitos de experiencias } \\
\text { prácticas. }\end{array}$ & $\begin{array}{l}\text { La etapa de experiencia práctica en la realización de trabajos } \\
\text { de contadores profesionales debe ser parte integrante } \\
\text { del programa de calificación. Este período debe ser lo } \\
\text { suficientemente largo e intenso para permitir a los candidatos } \\
\text { demostrar que han adquirido los conocimientos, habilidades, } \\
\text { valores, ética y actitud profesionales necesarios para realizar su } \\
\text { trabajo con competencia profesional y seguir desarrollándose } \\
\text { a lo largo de sus carreras. El período de experiencia práctica } \\
\text { debe ser al menos de tres años }\end{array}$ \\
\hline
\end{tabular}




\begin{tabular}{|c|c|c|}
\hline Norma & Nombre & Concepto de competencia \\
\hline IES 6 & $\begin{array}{c}\text { Evaluación de las } \\
\text { capacidades y competencias } \\
\text { profesionales. }\end{array}$ & $\begin{array}{l}\text { Establece los requisitos para una evaluación final de las } \\
\text { capacidades y la competencia de un pasante antes de la } \\
\text { calificación como contador profesional. Esta IES se ocupa } \\
\text { de la evaluación de las capacidades profesionales (es decir, } \\
\text { los conocimientos, habilidades, valores, ética y actitud } \\
\text { profesionales) adquiridos mediante programas de formación } \\
\text { profesional. Las capacidades y competencia profesionales de } \\
\text { los aspirantes deben ser evaluadas formalmente antes de la } \\
\text { concesión de la calificación para el ejercicio de la profesión. }\end{array}$ \\
\hline IES 7 & $\begin{array}{c}\text { Desarrollo } \\
\text { profesional continuo: } \\
\text { Un programa de aprendizaje } \\
\text { permanente y desarrollo } \\
\text { continuo de la competencia } \\
\text { profesional. }\end{array}$ & $\begin{array}{l}\text { Esta IES regula cómo los contadores profesionales cumplen } \\
\text { sus obligaciones de competencia permanente. Los organismos } \\
\text { miembros deben fomentar la importancia del mejoramiento } \\
\text { continuo de las competencias y el compromiso de aprendizaje } \\
\text { permanente para todos los contadores profesionales. }\end{array}$ \\
\hline IES 8 & $\begin{array}{l}\text { Requisitos de competencias } \\
\text { que deben reunir los } \\
\text { auditores profesionales. }\end{array}$ & $\begin{array}{l}\text { Para adquirir las capacidades y competencias requeridas a } \\
\text { los auditores profesionales, los individuos pueden necesitar } \\
\text { un nivel de formación y desarrollo que va más allá del que se } \\
\text { necesita para la calificación como contadores profesionales. } \\
\text { Las capacidades y competencia profesional deben evaluarse } \\
\text { antes de que los individuos desempeñen el papel de auditor } \\
\text { profesional. }\end{array}$ \\
\hline
\end{tabular}

Fuente: Valero-Patiño-Duque (2013).

A su vez, también han existido lineamientos y conceptos emitidos por otras instituciones de nivel internacional sobre la formación y competencia en el ejercicio contable, como la Comisión Económica para América Latina - CEPAL, la Organización para la Cooperación y el Desarrollo Económico - OCDE, el proyecto Tuning, la Conferencia de las Naciones Unidas para el Comercio y el Desarrollo -UNCTAD (Vásquez y Patiño, 2015).

Es de resaltar que la IFAC preestablece por encima de ciertas instituciones frente al tema en desarrollo, ya que por medio de su Consejo de Normas Internacionales de Educación (IAESB) emiten la gran mayoría de directrices frente a la formación profesional en contabilidad, y además sus requerimientos sobre la evaluación de capacidades y competencias, van muy ligados a las recomendaciones que dio el Banco Mundial en el 2003 por medio del informe ROSC, donde hace un llamado de atención tanto a los requisitos para acceder a la práctica profesional como a la calidad en los contenidos impartidos en la formación profesional de los futuros contadores públicos.

Sobre lo anterior en aras de generar ciertas apreciaciones sobre el desarrollo de prácticas históricas de la formación tanto de la profesión en Colombia como de la praxis formativa, se hace necesario evaluar desde la academia la condición de todo lineamiento internacional frente al perfil del contador público colombiano, si bien el discurso o voluntad de la verdad es un procedimiento 
Rodelo, M., y Chamorro, C. Competencias genéricas en los programas de contaduría pública...

legitimado por las condiciones de experticia, el análisis y generación a luz de lo local también es válido y es un deber rescatarlo; Foucault (1970, citado en Maldonado, 2010) expresa que la producción del discurso se vale de procedimiento de exclusión, uno de ellos es la denominada voluntad de verdad, en la cual lo verdadero y lo falso dependen de los sistemas institucionales que emitan las regulaciones.

\section{III.II. En el aspecto Nacional}

Por medio de la resolución 3459 de 2003 del Ministerio de Educación Nacional "Por la cual se definen las características específicas de calidad para los programas de formación profesional de pregrado en Contaduría Pública", se definen las características específicas de calidad para los programas de formación profesional en pregrado de contaduría pública (Valero, et al. 2013), donde en su artículo 2, Aspectos curriculares, preestablece que "en la propuesta de programa se hará explícitos los principios y propósitos de formación desde una perspectiva integral, considerando, las características y las competencias que adquiera y desarrolla el profesional" (Ver figura 1):

Figura 1: Objetivo de prestablecimiento de competencias dentro los programas de contaduría pública en Colombia.
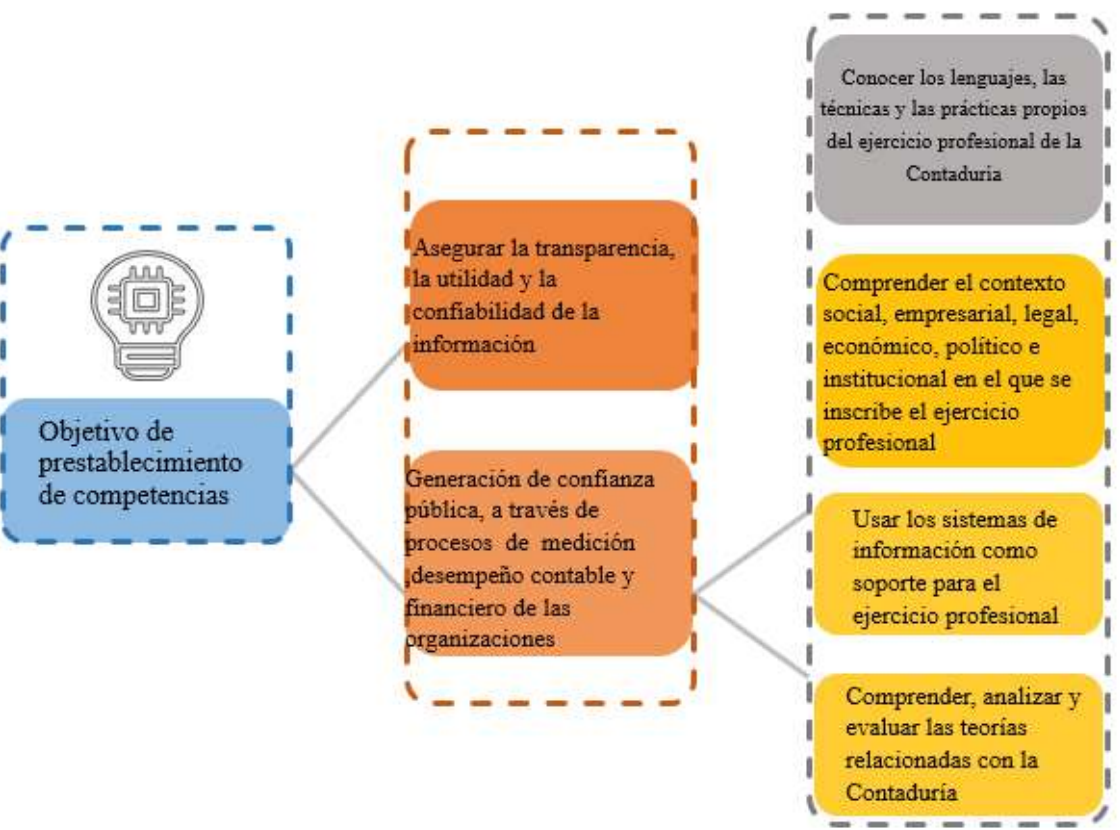

Fuente: Elaboración propia basado en Resolución 3459 (2003). 
Y para lograr el anterior objetivo, los programas de contaduría pública se basarán en áreas mínimas para la formación integral de los estudiantes (ver figura 2). Ahora bien, existe el Instituto Colombiano para la Evaluación de la Educación (ICFES), entidad encargada de evaluar dichas competencias por medio de un examen único profesional en todas las áreas del conocimiento en las distintas profesiones, denominado Examen de Calidad de la Educación Superior (Saber Pro), donde mide las competencias interpretativa, argumentativas y propositivas (ICFES, 2014); es decir, "es la encargada de la evaluación de la educación en todos sus niveles y de adelantar investigaciones sobre factores que inciden en la calidad educativa con la finalidad de ofrecer información que contribuya al mejoramiento de esta” (ICFES, 2004).

Figura 2: Área mínima para la formación contable integral en Colombia.

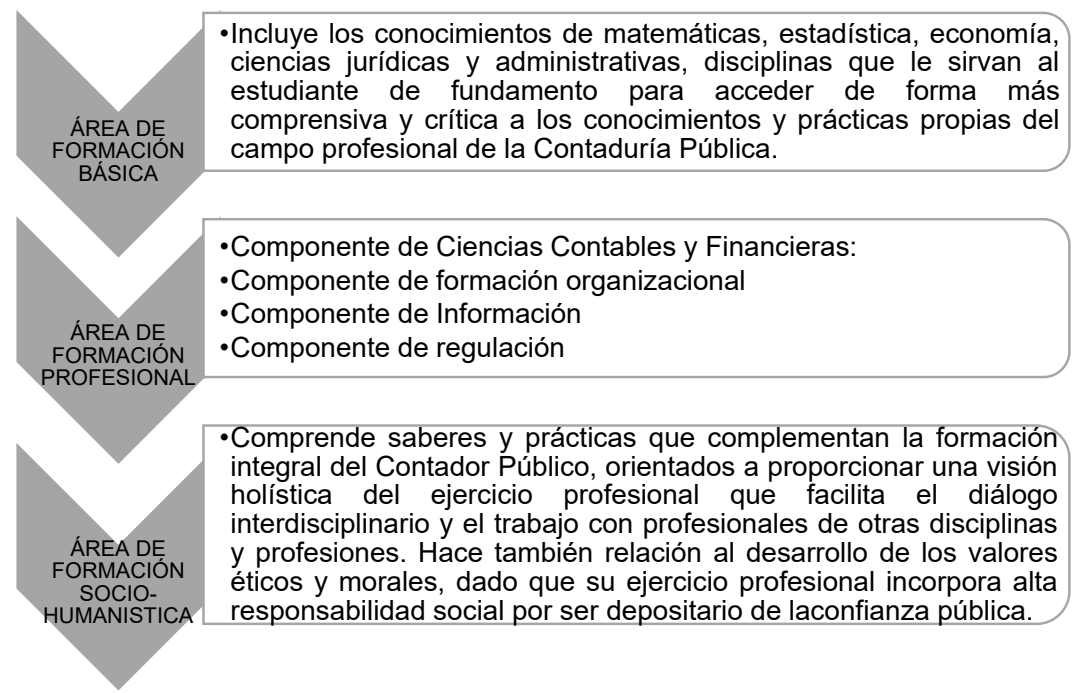

Fuente: Elaboración propia basado en Resolución 3459 (2003).

Hasta aquí llega un acercamiento sobre el desarrollo de las competencias y sus aproximaciones al campo educativo, en especial en el plano de formación contable, desde una visión institucional, que ha arrojado una ruta y espacios que han seguido los programas de pregrado en contaduría pública en Colombia a lo largo de los años, que, sin duda alguna, sus máximos postulados preestablecen un comportamiento motriz.

A continuación, se presenta una aproximación teórica y contextual de las competencias genéricas, permitiendo tener un bosquejo textual para el análisis de la importancia de las competencias- genéricas o transversales en la formación universitaria y por ende en el estudiante, especialmente en los estudiantes de contaduría pública. 
Rodelo, M., y Chamorro, C. Competencias genéricas en los programas de contaduría pública...

Las competencias genéricas, parten del desarrollo comportamental del ser humano o de la individualidad del ser, como aspecto motriz de generación de conocimiento y comportamiento semiótico, adquirido desde los niveles educativos básicos y medio del hombre, donde ha adquirido la base necesaria para avanzar en su proyecto educativo profesional y humano, tal y como lo expresa Corominas (2001) las competencias genéricas o saber comportamental "son atributos personales de carácter cognitivo, social, actitudinal o valorativo que enriquecen el comportamiento profesional" (p. 301).

González \& González (2008) también las llaman a partir del Proyecto Tuning América Latina (2007) competencias de orden cognitivo y de orden motivacional, clasificadas en:

- Competencias instrumentales, de orden metodológico o de procedimiento, tales como la capacidad de análisis y síntesis, de organización y planificación, y de gestión de información.

- Competencias personales, tales como la capacidad para el trabajo en equipo, la habilidad para el manejo de las relaciones interpersonales, el compromiso ético.

- Competencias sistémicas, que se manifiestan en el aprendizaje autónomo, la adaptación a nuevas situaciones, la creatividad y el liderazgo, entre otras. (p.193)

En esa misma línea, Tobón (2006, citado en Rueda et al, 2020) también las "caracteriza como sociales, genéricas o transversales que se encuentran ligadas a cualquier actividad o tarea -o a varias- y resalta su importancia con las siguientes características" (p.259) (Ver figura 3).

Figura 3: Características de las competencias Genéricas

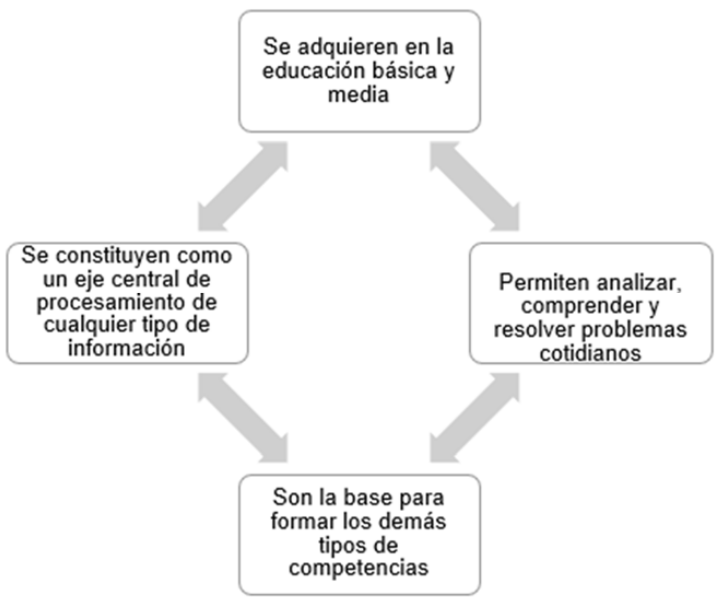

Fuente: Elaboración propia basado en Tobón (2006). 
Así pues, se resalta su preponderancia general y transversal en la formación del estudiante a lo largo de vida educativa, y en especial al finalizar su etapa universitaria, en ese sentido, el desarrollo profesional del futuro contador público, denota la necesidad de resaltar este tipo de competencias dentro de su formación, dado el carácter de responsabilidad fiscal y social que posee el contador público como sujetos de cambios dentro de las organizaciones y/o empresas, hasta de la misma sociedad, por ende, se requiere unas cualidades humanas pertinentes, orientadas a una buena ejecución laboral en cualquiera que fuera su especialización de campo de acción, organizaciones, docente, investigador, administrativo, etc., en búsqueda de su consolidación como profesional y agente motriz en los cambios socio-educativos de su entorno.

Esto último, toma mucha relevancia en el campo profesional-laboral, tal como lo hace ver el Informe Delors (Delors, 1996:79, citado en Corominas, 2001):

En lugar de cualificación, todavía muy impregnada de la idea de habilidad material, los empresarios reclaman cada vez más la competencia», que es una especie de composición propia de cada individuo que combina la capacitación y cualificación, adquirida por la formación técnica y profesional, con el comportamiento social, la aptitud para el trabajo en equipo, la iniciativa, el gusto por el riesgo... En el concepto de competencia se integra el saber, el saber hacer y el saber ser. (p. 301)

Sin embargo, esta transversalidad y generalidad de las competencias genéricas requiere un proceso motriz y semiótico que permita también poder orientar a partir de las cualidades cognitivas y humanas, a los respectivos entes o instituciones evaluadoras, la mejor manera de medir dichas competencias a partir de supuestos sensorial-motrices del comportamiento humano que, para el caso colombiano, tal y como lo mencionamos anteriormente, la institución encargada es el Instituto Colombiano para la Evaluación de la Educación (ICFES).

Por consiguiente, las evaluaciones como aspecto estructural de los distintos procesos desarrollados en la formación profesional, son elementos determinantes en la fijación de la forma de cómo se proyecta el perfil de estudio del estudiante y acción de la labor docente en los programas de pregrado (Villa y Poblete, 2011), y en este caso, en los programas de contaduría pública, que deberán contemplar íntegramente acciones y situaciones a partir de su campo de acción de manera general; por ello, planteándose actividades progresivamente más complejas y con criterios más exigentes (Yaniz y Villardón, 2012, citado en Villarroel y Bruna, 2014), guardando una relación directa a partir de los componentes curriculares del programa y del centro de educación superior.

En síntesis, se hace pertinente poseer un sistema de evaluación que permita observar, mediar y analizar las referencias desarrolladas en los estudiantes universitarios y más en el caso de los estudiantes de contaduría pública, tal como lo expresan Villarroel y Bruna (2014), la evaluación de competencias demanda planificar un sistema de evaluación y preparación que permita 
Rodelo, M., y Chamorro, C. Competencias genéricas en los programas de contaduría pública...

vincular las competencias con sus indicadores y evidencias de modo que pueda establecerse una valoración o calificación que pueda justificarse en términos de resultados de aprendizaje de la competencia; así pues, es necesario conocer de fondo la instituciones, parámetros y niveles de conceptuales a evaluar dentro de las competencia genéricas.

Paralelamente, Yaniz y Villardón (2012), citado en Villarroel y Bruna (2014), expresa lo siguiente:

Evaluar una competencia genérica implica hacer un juicio de valor sobre las prácticas que definen esta competencia, basándose en criterios de ejecución a partir de la evidencia. Para ello, es necesario conocer con claridad qué se va a evaluar y los distintos niveles de adquisición de la competencia en cuestión. (p. 29)

En ese sentido, para el caso colombiano y en lo que respecta para los programas de contaduría pública, el Instituto Colombiano para la Evaluación de la Educación establece una estructura evaluativa de competencias tanto genéricas como específicas, condensadas en el instrumento evaluativo de las pruebas Saber Pro (Ver Tabla 3).

Tabla 3: Estructura de las competencias evaluadas en las pruebas Saber Pro 2018.

\begin{tabular}{ll}
\hline \multicolumn{1}{c}{ Módulos } & \multicolumn{1}{c}{ Estructura } \\
\hline & Comunicación escrita \\
& Razonamiento cuantitativo \\
Módulo de competencias genéricas & Lectura crítica \\
& Competencias ciudadanas \\
& Ingles \\
\hline Módulo de competencias especificas & Gestión financiera \\
& Información y control contable \\
& Formulación, evaluación y gestión de proyectos \\
\hline
\end{tabular}

Fuente: Elaboración propia basado en ICFES, 2018.

De igual manera, el Instituto Colombiano para la Evaluación de la Educación define bajo su marco legal, el conjunto de elementos que forjan obtener un buen desempeño en contextos complejos y auténticos, que a su vez co-integran $\mathrm{y}$ activan conocimientos generales y disciplinares, que facilitan el ejercicio profesional y social del estudiante (Ver tablas 4 y 5). 
Tabla 4: Descripción de los módulos evaluados como competencias genéricas por el ICFES 2018.

\begin{tabular}{ll}
\hline \multicolumn{1}{c}{ Módulos } & \multicolumn{1}{c}{ Descripción } \\
\hline Comunicación escrita & $\begin{array}{l}\text { Evalúa la competencia para comunicar ideas por escrito referidas a un } \\
\text { tema dado. Los temas sobre los que yace la escritura son de dominio } \\
\text { público, no requieren conocimientos especializados. }\end{array}$ \\
\hline \multirow{3}{*}{ Razonamiento cuantitativo } & $\begin{array}{l}\text { Evalúa competencias relacionadas con las habilidades matemáticas para } \\
\text { desempeñarse adecuadamente en contextos cotidianos que involucran } \\
\text { información de carácter cuantitativo }\end{array}$ \\
\hline \multirow{2}{*}{ Lectura crítica } & $\begin{array}{l}\text { Evalúa las capacidades de entender, interpretar y evaluar textos que } \\
\text { pueden encontrarse tanto en la vida cotidiana, como en ámbitos } \\
\text { académicos no especializados }\end{array}$ \\
\hline Ingles & $\begin{array}{l}\text { Evalúa los conocimientos y habilidades que posibilitan la construcción de } \\
\text { marcos de comprensión del entorno, los cuales promueven el ejercicio } \\
\text { de la ciudadanía y la coexistencia inclusiva según la Constitución política }\end{array}$ \\
\hline & $\begin{array}{l}\text { Evalúa la competencia para comunicarse efectivamente en inglés. Esta } \\
\text { competencia, alineada con el Marco Común Europeo, permite clasificar a } \\
\text { los examinados según su nivel de desempeño }\end{array}$ \\
\hline
\end{tabular}

Fuente: Elaboración propia basado ICFES 2018.

Tabla 5: Descripción de las competencias evaluadas en los módulos genéricos por el ICFES 2018.

\begin{tabular}{|c|c|}
\hline Módulos & Competencias \\
\hline Comunicación escrita & $\begin{array}{l}\text { Planteamiento que se hace en el texto } \\
\text { Organización del texto } \\
\text { Forma de la expresión }\end{array}$ \\
\hline Razonamiento cuantitativo & $\begin{array}{l}\text { Interpretación y representación. } \\
\text { Formulación y ejecución. } \\
\text { Argumentación. }\end{array}$ \\
\hline Lectura crítica & $\begin{array}{l}\text { Identificar y entender los contenidos locales que conforman un texto. } \\
\text { Comprender cómo se articulan las partes de un texto para darle un } \\
\text { sentido global. } \\
\text { Reflexionar a partir de un texto y evaluar su contenido. }\end{array}$ \\
\hline Competencias ciudadanas & $\begin{array}{l}\text { Conocimiento. } \\
\text { Argumentación. } \\
\text { Multiperspectivismo. } \\
\text { Pensamiento sistémico. }\end{array}$ \\
\hline Ingles & Comunicación y entendimiento efectivo en un segundo idioma (Ingles) \\
\hline
\end{tabular}

Fuente: Elaboración propia basado ICFES 2018.

Así pues, se resalta la alta densidad de políticas, directrices y/o pautas de los distintos entes e instituciones de tipo internacional y nacional que orientan un paradigma de formación perentoria hacia las competencias específicas- 
Rodelo, M., y Chamorro, C. Competencias genéricas en los programas de contaduría pública...

genéricas, preestableciendo la importancia relativa del carácter integral de la formación amplia que requiere el futuro contador público colombiano, donde las competencias genéricas son consideradas un complemento de esencialidad con las específicas, como un todo, en la construcción de un profesional contable competente y humano, resaltando que estas últimas son más perdurables (Corominas, 2001) que las específicas, que cambian acorde a las nuevas tecnologías y realidades.

En mira al fortalecimiento para la preparación de las pruebas Saber Pro el programa de contaduría pública de la Universidad del Atlántico en orientación por la Facultad de Ciencias Económicas y la Vicerrectoría de Docencia (2016), en el marco de garantizar buenos indicadores educativos, pero a su vez poder proyectar un buen profesional en el mundo laboral, académico e investigativo, preestablece las siguientes estrategias:

- Programas de capacitaciones y talleres a docentes respecto a la metodología de evaluación de las pruebas Saber Pro.

- Plan de mejoramiento ante pruebas saber dentro del marco de la acreditación y autoevaluación de programas, que incluyan actividades desde los planteamientos curriculares hasta la motivación y compromiso de los diferentes actores involucrados en el proceso.

- Programa de capacitación y talleres, como preparatorio para estudiantes de último año relacionado con las metodologías y en cada una de las componentes de las pruebas saber. (p. 56)

\section{Metodología}

La investigación desarrolló un enfoque metodológico cuantitativo, extraído a través de una revisión sistemática y solicitudes enviadas al programa de contaduría pública de la Universidad del Atlántico. Se realizó una recopilación de datos numéricos a partir de los resultados del Examen de Calidad de la Educación Superior (Saber Pro) en el programa de contaduría pública de la universidad en mención entre los años 2016 a 2018.

En la etapa de diseño, se optó por la realización de una revisión descriptiva, con el ánimo de hacer emerger conceptos útiles que fueran guiando la búsqueda literaria. La sistematización del material fue desarrollada según los módulos establecidos por el marco legal de las pruebas Saber Pro (1) Comunicación escrita (2) Razonamiento cuantitativo (3) Lectura crítica (4) Competencias ciudadanas (5) inglés. Luego fueron estudiadas por periodos de tiempo, desde una perspectiva analítica.

Finalmente, en un proceso de reordenación, integración y priorización, emergieron conclusiones finales que permitieron cumplir con el objetivo planteado, al ser comparadas y complementadas por las teorías iniciales. La metodología se resume en la Tabla 6. 
Tabla 6: Diseño Metodológico.

\begin{tabular}{ll}
\hline \multicolumn{1}{c}{ Ítems } & \multicolumn{1}{c}{ Detalle } \\
\hline Enfoque & Cuantitativo \\
Tipos de estudio & Descriptivo \\
Población & Universidad del Atlántico \\
Periodo & $2016-2018$ \\
Técnica & Revisión descriptiva \\
Instrumento & Tablas de análisis \\
Análisis de datos & Módulos de pruebas SaberPro \\
Programa para el análisis & Excel Versión 2013 \\
\hline
\end{tabular}

Fuente: Elaboración propia (2020).

\section{Resultados}

El programa de contaduría pública de la Universidad del Atlántico entre el 2016 a 2018, detalla que el promedio de sus resultados está por encima del promedio de su grupo de referencia y de la media nacional, asunto de vital importancia en la formación del ser y de proyección como programa de pregrado, donde las competencias de razonamiento cuantitativo y lectura crítica, son las más altas proporcionalmente durante estos años.

De manera relevante se expresa durante el periodo de 2016; la prueba fue presentada por doscientos treinta y cinco (235) estudiantes, seguidamente en el año 2017 se redujo a doscientos quince (215) alumnos y finalmente para el periodo de 2018 se reflejan doscientos diecisiete (217) estudiantes; reflejando una cantidad poco variable durante el rango de estudio. Ahora bien, los resultados de las pruebas Saber Pro se presentan en el siguiente orden (1) Comunicación escrita (2) Razonamiento cuantitativo (3) Lectura crítica (4) Competencias ciudadanas y (5) inglés.

Los hallazgos en la competencia de comunicación escrita reflejan que existe una variación significativa con respecto a los años estudiados puesto que en el año 2016 se mantiene un promedio de 153,61 y para 2017-2018 el promedio disminuye paralelamente en 145,44 y 142,85 (Ver figura 4).

Por otro lado, en la competencia de razonamiento cuantitativo se ilustran unos promedios estandarizados debido a que en el 2016 se refleja un resultado de 162,42 con respecto al grupo de referencias y posteriormente 2017-2018 denotan un promedio de 160,66 y 160,88 demostrando que los estudiantes mantienen unas capacidades y habilidades asertivas en dicha competencia (Ver figura 5).

Los resultados precedentes, reafirman lo establecido por el Instituto Colombiano para la Evaluación de la Educación (2018), en cuanto a que la asertividad de los estudiantes en la competencia de razonamiento cuantitativo 
Rodelo, M., y Chamorro, C. Competencias genéricas en los programas de contaduría pública...

consolida sus habilidades matemáticas que les permite un desempeño adecuado en contextos cotidianos que involucren información de carácter cuantitativo.

Figura 4: Promedio Comunicación escrita.

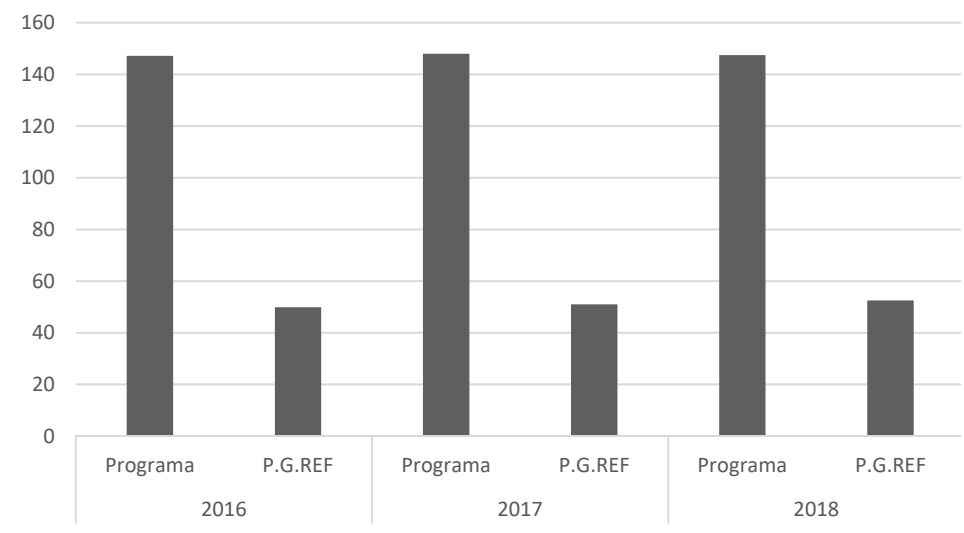

Fuente: Elaboración propia basado en resultado ICFES, 2016.

Figura 5: Promedio Razonamiento Cuantitativo.

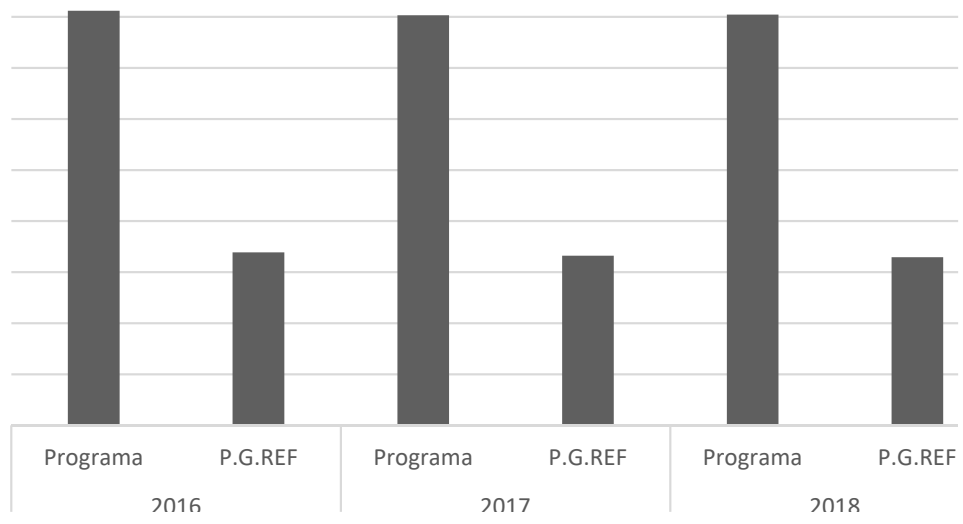

Fuente: Elaboración propia basado en resultado ICFES, 2017.

Posteriormente, la figura 6 ilustra que los estudiantes de la universidad del atlántico deben fortalecer sus habilidades en las competencias de lectura crítica puesto que, aunque el resultado no es tan preocupante, es importante generar desde la institución estrategias que permitan aumentar los promedios ya que 2016 refleja un 156,92 y entre 2017 y 2018 se denota un promedio 158,35 y 154,10.

Así pues, se toma en consideración los argumentos de Corominas (2001), quien expresa la necesidad importante de potencializar en los estudiantes de contaduría pública los ejes competentes de lectura crítica para entender, 
interpretar y evaluar textos disciplinares que facilitan el ejercicio profesional y social del estudiante.

Figura 6: Promedio Lectura Crítica.

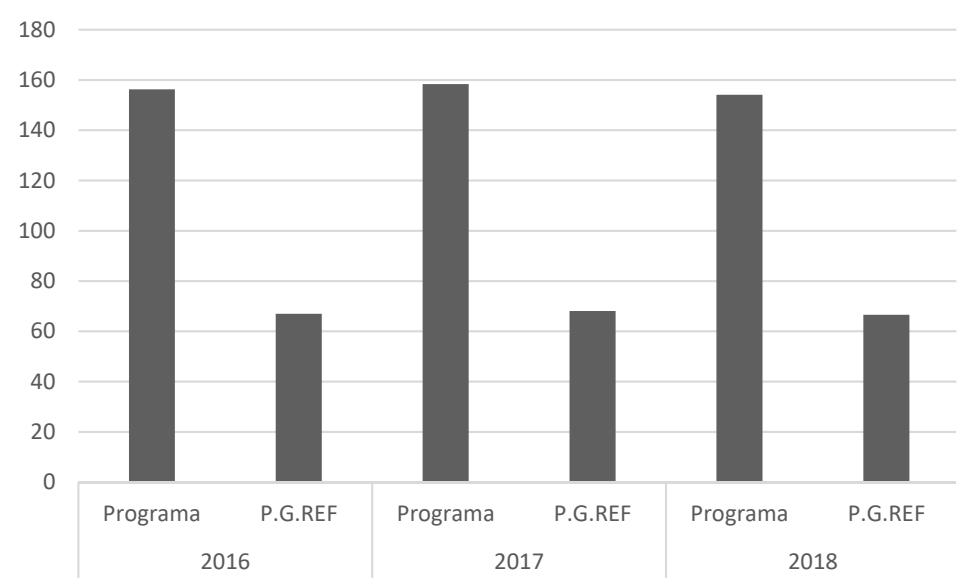

Fuente: Elaboración propia basado en resultado ICFES, 2017.

No obstante, un resultado similar se devela en competencias ciudadanas en donde se halla que en 2016 se obtuvo un promedio de 153,61 y disminuyó significativamente en $2017-2018$ con un 145,44 y 142,85 . Lo anterior conduce a reflexionar que las bases educativas para fortalecer esta competencia tal vez no están siendo eficientes; sin desconocer la responsabilidad de los estudiantes quienes también deben incrementar sus esfuerzos para fortalecer dicha competencia (Ver figura 7).

Figura 7: Competencias ciudadanas.

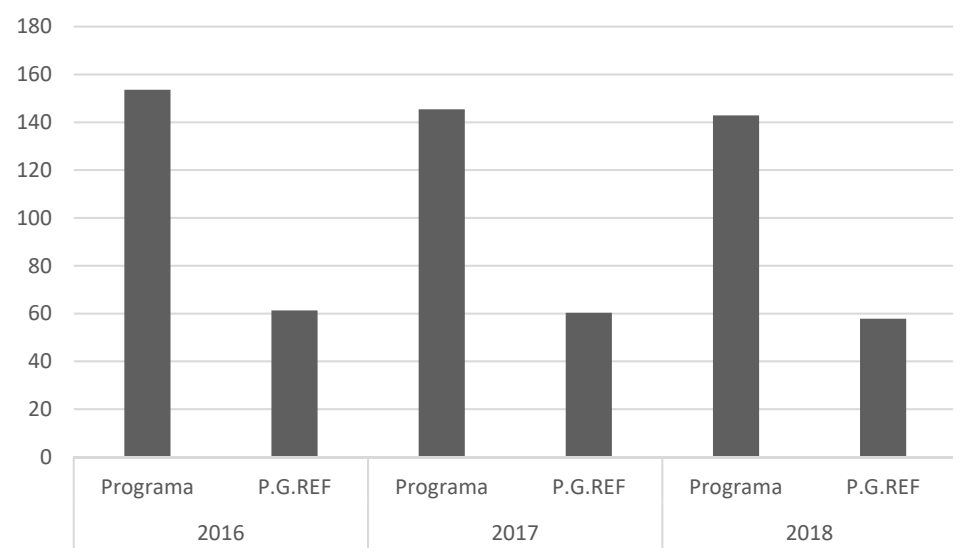

Fuente: Elaboración propia (2020). 
Rodelo, M., y Chamorro, C. Competencias genéricas en los programas de contaduría pública...

Finalmente, la competencia de inglés ilustrada en la figura 7 demuestra un promedio básico que puede robustecerse a través de diferentes mecanismos y didácticas que motiven a los estudiantes a formarse arduamente en esta competencia. Los resultados evidencian un promedio de $(152,14)$ para 2016 , $(151,73)$ en 2017 y finalmente $(155,32)$ en 2018 . Estos hallazgos re-afirman lo planteado por Chan et al. (2017) quien expresa que los conocimientos bilingües permiten alinearse con los avances teóricos en materia disciplinar que se desarrollan a nivel internacional, a su vez integran un valor agregado en el ejercicio profesional.

En este sentido, se logra analizar que el constructo de los módulos de competencias ciudadanas, lectura crítica, razonamiento cuantitativo, comunicación escrita e inglés presenta divergencias entre sí. Los resultados demuestran que el programa de contaduría pública de la Universidad del Atlántico mantiene un promedio constante mayor de 140 entre los años 2016 y 2018.

Figura 8: Promedio del componente de inglés.

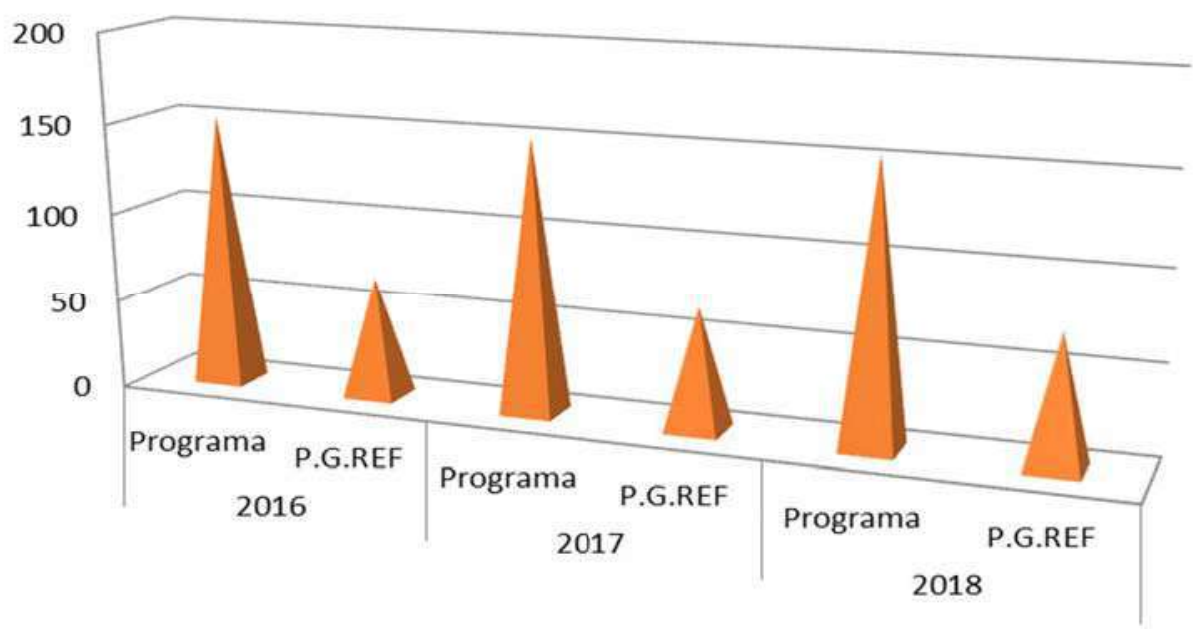

Fuente: Elaboración propia basado en resultado ICFES, 2018.

Ahora bien, las primeras figuras logran demostrar que el número de estudiantes que presentan las pruebas (Saber Pro) es variable en cada periodo. Así mismo existe una variabilidad en los resultados promedio de cada módulo de estas competencias que tienen una tendencia positiva en cuanto al mejoramiento de los resultados con el transcurrir del tiempo. Eso permite generar una distinción en el programa de contaduría pública frente a los demás programas de la ciudad. Con ello, se considera importante reflejar una compilación de todos los promedios que se obtuvieron por el programa de contaduría pública en cada uno de los componentes evaluados entre el 2016 y 2018. 
Figura 9: Comparación de resultados con el promedio del grupo de referencia.

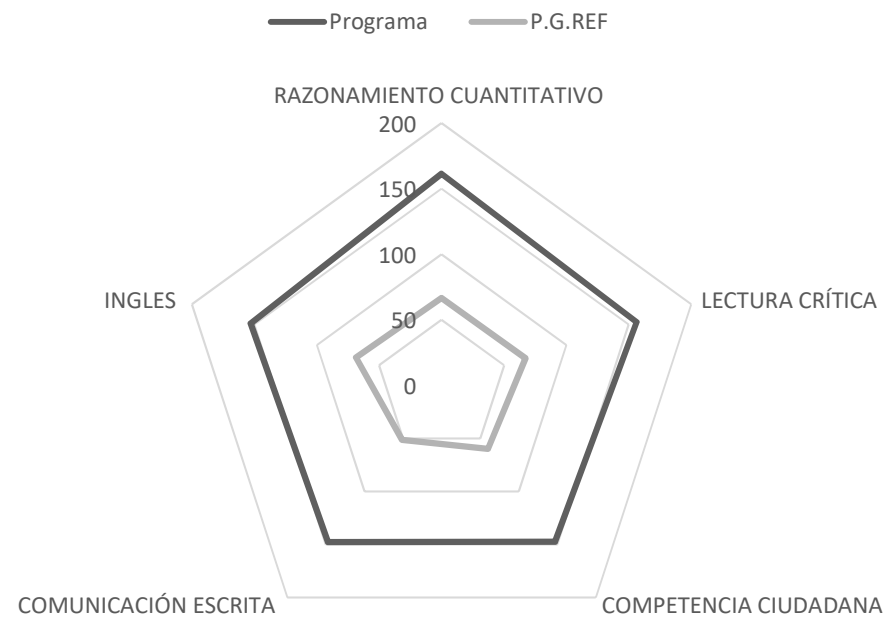

Fuente: Elaboración propia basado en resultado ICFES, 2016 -2018.

Teniendo en cuenta que el grupo de referencia es reconocido como el conjunto de programas que tienen características de formación semejantes, que tienen combinaciones de módulos de competencias específicas similares. La figura 8 logra ilustrar que el programa de contaduría pública de la Universidad del Atlántico está por encima del grupo de referencia en los 5 componentes evaluados a nivel nacional por el ICFES. Logrando de esta manera que se mantuviera el promedio estadístico durante 3 años consecutivos por parte del Programa de Contaduría Pública.

Figura 10: Resultados Globales Competencias Genéricas 2016.

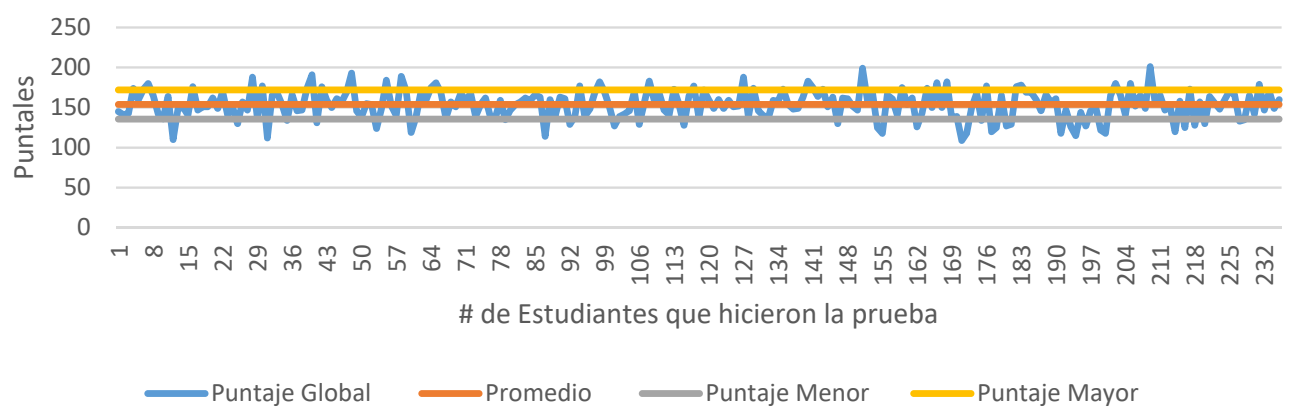

Fuente: Elaboración propia basado en resultado ICFES, 2018. 
Rodelo, M., y Chamorro, C. Competencias genéricas en los programas de contaduría pública...

Figura 11: Resultados Globales Competencias Genéricas 2017.

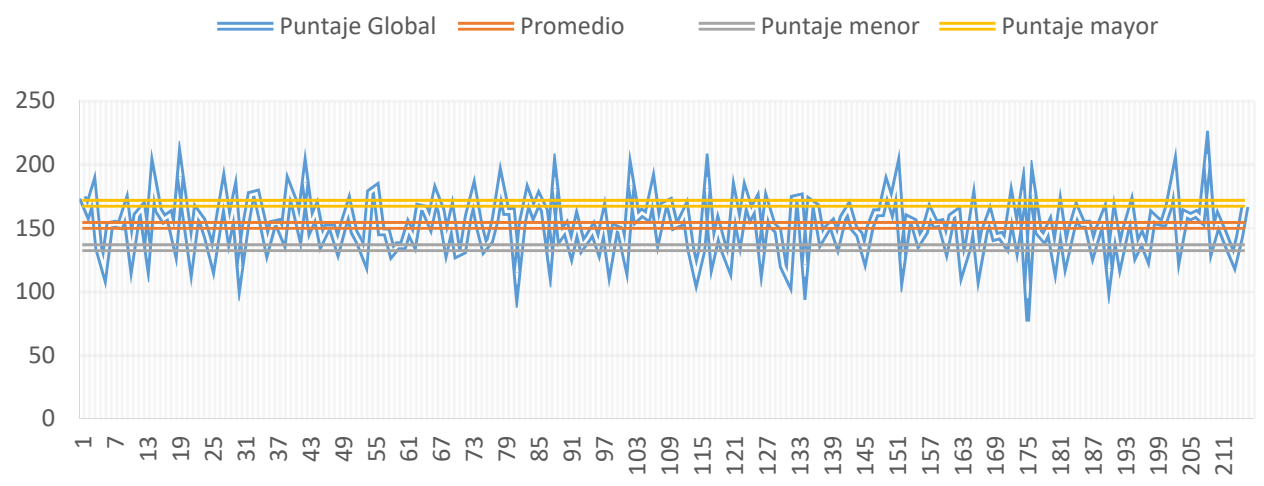

Fuente: Elaboración propia basado en resultado ICFES, 2018.

Figura 12: Resultados Globales Competencias Genéricas 2018.

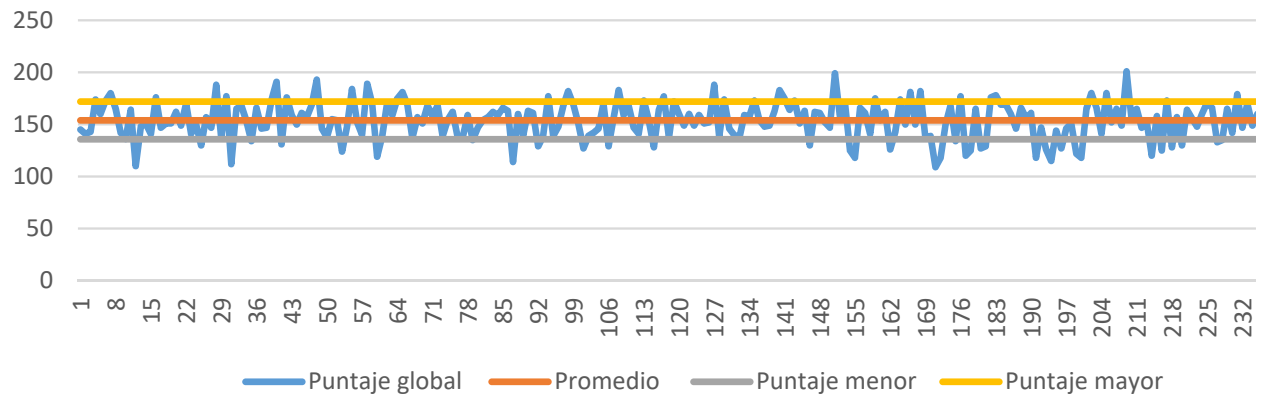

Fuente: Elaboración propia basado en resultado ICFES, 2018.

Las figuras 9 -11, proyectan las variaciones (Desviación Estándar) de los distintos resultados globales de cada estudiante de contaduría pública en las competencias genéricas, arrojando un comportamiento promedio y mayoritariamente uniforme en los módulos evaluativos en cada uno de los respectivos años del 2016 a 2018. Logrando así demostrar que son muy pocas las divergencias y las brechas entre los estudiantes que obtienen altos resultados y los que están muy por debajo dentro de la misma institución.

Lo anterior, permite reafirmar los legados teóricos de Tobón (2006) y Villa y Poblete (2011) en razón a que se reconoce un comportamiento favorable en los resultados globales de las competencias genéricas de la UA entre 2016-2018, conduciendo a una preponderancia general y transversal en la formación del estudiante a lo largo de la vida educativa. Con ello, se observa que los estudiantes tienen competencias óptimas para analizar, comprender y resolver problemas cotidianos. Así mismo, los resultados dan cuentan de su 
consolidación como profesionales y agentes motrices en los cambios socioeducativos de su entorno (Corominas, 2001).

Adicionalmente, se presenta un comparativo de los resultados de las competencias genéricas de los programas de contaduría pública y afines ofertados en la ciudad de Barranquilla, lo que arroja que la Universidad del Atlántico ocupa el segundo lugar entre el periodo 2016 al 2018, con resultado para el año 2016 de un promedio de (154,33), $2017(152,83)$ y $2018(152,13)$, sobrepasando la media nacional de (150); el primer lugar lo ocupa la Universidad del Norte con un promedio para el $2016(167,27), 2017(163,48)$ y $2018(167,27)$. Ver figura 12.

Figura 13: Resultados Competencias Genéricas/Barranquilla 2016- 2018.

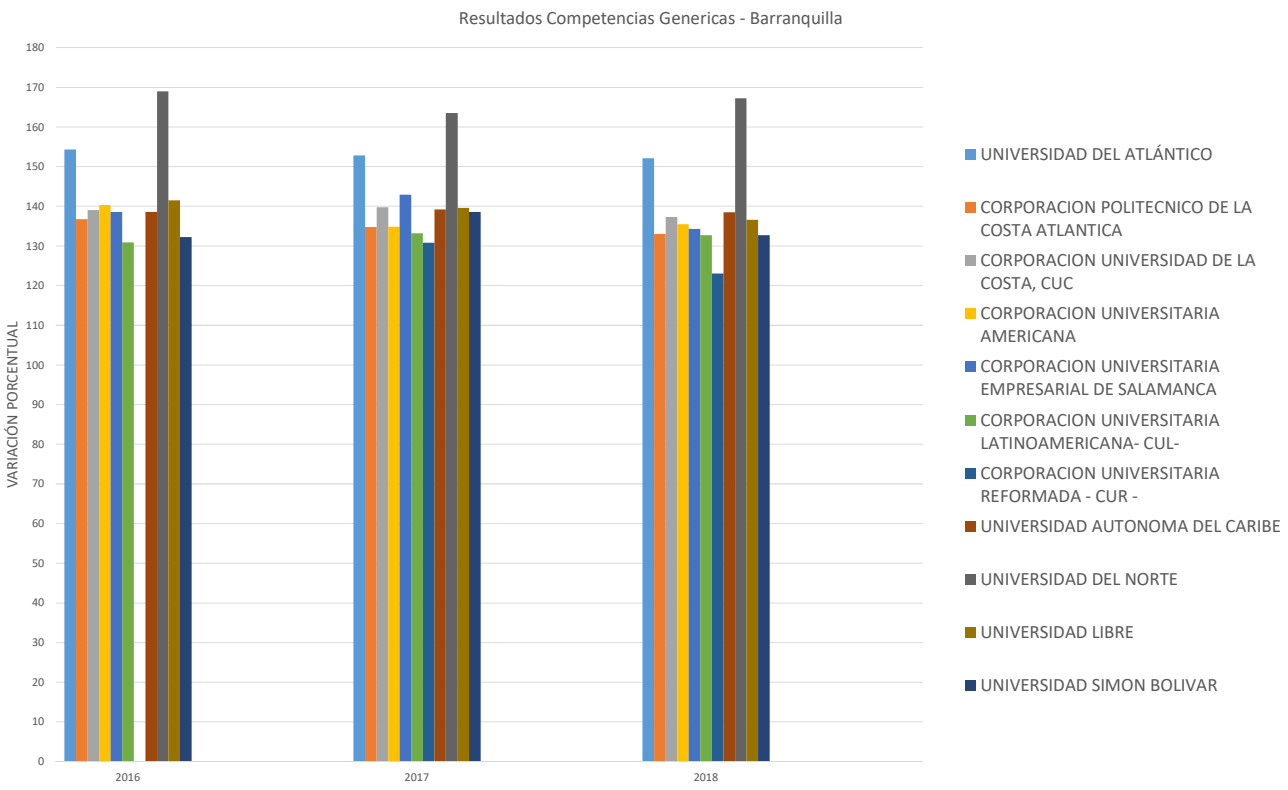

Fuente: Elaboración propia basado en resultado ICFES, 2018.

Lo anterior dicta que la Universidad del Atlántico en comparación con los 11 programas de pregrado de las otras Instituciones de Educación Superior que ofertan el programa de contaduría pública y afines, se encuentra en un rango superior, junto con la Universidad del Norte, referenciando que, de una u otra manera, los profesionales de estas universidades salen con un plus mucho mayor que las otras; no obstante, la referenciación anterior no se hace con el fin de preestablecer qué centro de educación superior es mejor o cuál no, es un deber entre todos los programas e IES, fortalecer la formación del profesional contable. 
Rodelo, M., y Chamorro, C. Competencias genéricas en los programas de contaduría pública...

\section{VI.Conclusiones}

El mundo contemporáneo, considerado como el mundo económico actual, está en un movimiento continuo que refleja un proceso en evolución perpetua. Es por ello que la formación en competencias profesionales se establece como un foco esencial de la educación superior actual, alineada a la formación integral del estudiante, buscando generar profesionales eficientes, éticos y responsables.

La presente investigación demostró que los centros de educación superior deben preocuparse constantemente por formar sujetos (Contables) con altas competencias el campo profesional y humano, puesto que cada vez es más imperante a la luz de las nuevas prácticas educativas. Así pues, surgió la necesidad de analizar los resultados (de las competencias genéricas) del Examen de Calidad de la Educación Superior (Saber Pro) de los estudiantes del programa de contaduría pública de la Universidad del Atlántico entre los periodos 2016-2018.

En razón a ello, las competencias genéricas dentro de los sistemas de educación contable de las Instituciones de Educación Superior, han tomado mucha fuerza en este último periodo de tiempo. Sin embargo, aún persiste la necesidad de seguir dándole la importancia relativa que se merece en el proceso de formación profesional de los estudiantes de contaduría pública. Se considera que los avances científicos y tecnológicos en la disciplina contable han permitido fortalecer las competencias genéricas en los contadores en formación (Roncancio et al., 2017).

Los resultados de la investigación demostraron que entre los periodos 2016 al 2018 los contadores en formación de la Universidad del Atlántico superan la media nacional en su grupo de referencia, estableciendo un buen nivel de competencia para su ejecución profesional y de desarrollo humano. Ahora bien, en cuanto a la población estudiantil que presentó la pruebas Saber Pro se identificó que la variación fue mínima; sin embargo, el año con mayor número de estudiantes fue 2016 en donde se ubican (235) y en el año 2017 se presenta el menor número de estudiantes con (215).

Así mismo, se concluye que durante el periodo de 2016-2018 los estudiantes de contaduría pública de la Universidad del Atlántico tuvieron un resultado mayor en el módulo de razonamiento cuantitativo con un promedio igual o superior a (160) según el grupo de referencia. Sin embargo, al analizar cuál es el componente en donde se deben generar esfuerzos para incrementarlo, se halla que el promedio más bajo en 2016 fue comunicación escrita con (147) y para 2017 y 2018 se refleja el componente de competencias ciudadanas con un promedio de (145) y (142) paralelamente. 
Lo anterior permite sintetizar que las competencias genéricas son necesarias para funcionar eficazmente como contador profesional y cumplir con las expectativas del público o terceros de la información. Entre tanto, se determina que los estudiantes de contaduría pública de la Universidad del Atlántico mantienen un liderazgo positivo respecto a su grupo de referencia, en cuanto a los componentes genéricos que deben tener para asegurar sus habilidades y aprendizaje en los servicios profesionales que han de ofrecer con responsabilidad.

Finalmente, se expresa que futuras investigaciones deberían analizar este tipo de temáticas con el objetivo de proyectar líneas de acción y de comportamiento institucional, logrando recopilar un conjunto de estrategias de propendan hacia la calidad del programa de contaduría pública desde el foco de las competencias genéricas y específicas. No obstante, estas investigaciones locales permitirán realizar comparaciones regionales y nacionales que proyectan una amplitud en términos de diagnóstico y oportunidades que se puede replicar bajo las percepciones de conocimiento y experiencia.

\section{Referencias bibliográficas}

Barnett, W. (2011). Effectiveness of early educational intervention. Science. 333(6045), 975978.

Cardona, J. y Zapata, M. (2006). Educación contable: Antecedente, actualidad y prospectiva. Tesis pregrado. Universidad de Antioquia.

Chan, C, Fong, E, Luk, L. y Ho, R. (2017). Una revisión de la literatura sobre desafíos en el desarrollo e implementación de competencias genéricas en el currículo de educación superior. Revista Internacional de Desarrollo Educativo. 57, 1-10.

Consejo de Normas Internacionales de Formación en Contaduría (2008). Manual de pronunciamientos internacionales de formación. Recuperado de: https://www.ifac. org/system/files/downloads/Spanish_Translation_Normas_Internacionales_de_ Formacion 2008.pdf

Corominas, E., (2001). Competencias genéricas en la formación universitaria. Revista de Educación. 325, 299-321.

Departamento de Calidad Integral de la Docencia - Facultad de Ciencias Económicas de la Universidad del Atlántico (2016). Informe Resultados Saber Pro - Pruebas Genéricas 2015 - Facultad De Ciencias Económicas. Barranquilla. Recuperado de: https://www. uniatlantico.edu.co/uatlantico/sites/default/files/4.\%20INFORME\%20RESULTADOS\%20 SABER\%20PRO\%202015\%20C.\%20ECON\%C3\%93MICAS.pdf

Franco, R. (2011). Reflexiones contables: teoría, regulación, educación y moral. Bogotá: Universidad Libre de Colombia.

Gracia, E. (2002). Estado Actual de la Educación Contable en Colombia. En C-Cinco, Del hacer al saber. Realidades y perspectivas de la educación contable en Colombia. Bogotá: Universidad del Cauca. 85-112. 
Rodelo, M., y Chamorro, C. Competencias genéricas en los programas de contaduría pública...

González, V. y González, R. (2008). Competencias genéricas y formación profesional: un análisis desde la docencia universitaria. Revista Iberoamericana de Educación. N. o 47, 185-209.

Hernández, C. y Rocha, D. (1996). Anotaciones Sobre el Concepto de Competencia en los Exámenes de estado. Evaluación y Cultura Escolar. Revista Colombiana Sobre procesos evaluativos. 2. 13-29.

Instituto Colombiano para la Evaluación de la Educación ICFES. (2012). Glosario de términos. Bogotá. Recuperado de: https://www.icfes.gov.co/glosario

Instituto Colombiano para la Evaluación de la Educación ICFES. (2014). Documentación del examen Saber PRO. Bogotá. Recuperado de: https:/www.icfes.gov.co/ documents/20143/518352/Documentacion\%20saber\%20pro.pdf

Instituto Colombiano para la Evaluación de la Educación ICFES. (2004). Marco Conceptual de la Fundamentación de la Prueba. Bogotá. Recuperado de: https://www.javeriana.edu. co/personales/hbermude/areacontable/particulares/arc_3846.pdf

Instituto Colombiano para la Evaluación de la Educación ICFES. (2018). Guía de Orientación Saber Pro. Módulos de Competencias Genéricas. Bogotá. Recuperado de: https://www. icfes.gov.co/documents/20143/496194/Guia\%20de\%20orientacion\%20modulos\%20 de\%20competencias\%20genericas-saber-pro-2018.pdf

Kincheloe, J., Steinberg, S. y Villaverde, L. (Eds.). (2004). Repensar la inteligencia: Hacer frente a los supuestos psicológicos sobre enseñanza y aprendizaje. Bogota: Ediciones Morata.

Macagnan, C., (2013). Teoría institucional: escrito teórico sobre los protagonistas de la escuela institucionalista de economía. Revista Base (Administração E Contabilidade) Da Unisinos. 10(2).130-141.

Maldonado, M. (2010). Currículo con enfoque de competencias. Bogotá: Ecoe Ediciones.

Martínez, G. (2007). La educación contable en el nuevo contexto de significación. Contaduría Universidad de Antioquia. 50, 43-76.

Mérida, R., y García, M. (2005). La formación de competencias en la universidad. 2005. Revista Electrónica Interuniversitaria de Formación del Profesorado. Vol. 8, núm. 1, febrero, 2005, 1-4.

Ministerio de Educación (2006). Estándares Básicos de Competencias en Lenguaje, Matemáticas, Ciencias y Ciudadanas. Guía sobre lo que los estudiantes deben saber y saber hacer con lo que aprenden. Bogotá: Imprenta Nacional de Colombia.

Ministerio de Educación (2006). Visión 2019 educación, propuesta para la discusión. Bogotá. Recuperado de: https://www.mineducacion.gov.co/cvn/1665/article-110603.html

Ministerio de Educación Nacional (30 de diciembre de 2003). Resolución 3459. Por la cual se definen las características específicas de calidad para los programas de formación profesional de pregrado en Contaduría Pública.

North, D. (1990). Institutions, institutional change and economic performance. Cambridge University Press. http://dx.doi.org/10.1017/CBO9780511808678

Patiño, R. y Santos, G. (2009a). Planes de estudio de contaduría pública en Colombia y las propuestas de formación profesional. En Revista Internacional Legis de Contabilidad $\mathcal{6}$ Auditoria. 37, 131-163. 
Pérez. M. (2012). Fortalecimiento de las competencias investigativas en el contexto de la educación superior en Colombia. Revista de investigaciones UNAD. Bogotá - Colombia No. 01, enero-junio.

Roncancio, A., Alvarado, G. y Murcia, N. (2017). Las competencias en la formación del profesional contable: una revisión de las posturas institucionales y educativas en Colombia. Revista Facultad de Ciencias Económicas: Investigación y Reflexión. 25(2), 83-103.

Rueda, G. Avendaño, W. y Luna, H. (2020). Las competencias genéricas en el proceso de formación del programa de contaduría pública de la Universidad Francisco de Paula Santander - Colombia. Revista Saber, Ciencia y Libertad. 15(1), 254 - 266.

Tobón, S. (2006). Aspectos básicos de la formación basada en competencias. (Informe Proyecto Mesesup) Bogotá: Universidad del Rosario. Recuperado de: https://maristas. org.mx/gestion/web/doctos/aspectos_basicos_formacion_competencias.pdf

Tobón, S. (2006). Las competencias en la educación superior. Políticas de calidad. Bogotá: ECOE. Valera, L. (2009). Competencias profesionales para los Estudiantes de la Carrera de Contabilidad y Finanzas. Cuadernos de Educación y Desarrollo. 1(1). 23-40.

Valero, G.; Patiño, R. y Duque. O. (2013). Competencias para el programa de contaduría pública: una aproximación conceptual. Contaduría Universidad de Antioquia. 62, 11-36.

Vásquez, N., y Patiño, R. (2015). El subsistema de formación contable en Colombia y México. Revista facultad de ciencias económicas. XXIII (1), 87-102.

Veblen, T. (1971). Teoría de la clase ociosa. México: Fondo de Cultura Económica.

Vega, R. (2015). La Universidad de la Ignorancia. Capitalismo académico y mercantilización de la educación superior. Bogotá: Ocean Sur.

Villa, A., y Poblete, M. (2011). Evaluación de competencias genéricas: Principios, Oportunidades y Limitaciones. Bordón. Revista de pedagogía. 63(1),147-170.

Villarroel, V., y Bruna, D. (2014). Reflexiones en torno a las competencias genéricas en educación superior: Un desafío pendiente. Psicoperspectivas. 13(1), 22-34.

Zlatkin-Troitschanskaia, O., Shavelson, R. y Kuhn, C. (2015). El estado internacional de la investigación sobre la medición de la competencia en la educación superior. Estudios en Educación Superior. 40(3), 393-411. 